\title{
A representatividade racial na função de diretora nos Centros Municipais de Educação Infantil do município de Curitiba em 2016: um limite para a democracia?
}

\section{The racial representativity in the function of director in the municipality of Curitiba in 2016: a limit for democracy?}

\author{
Marcus Quintanilha da Silva* \\ Danieli D'Aguiar Cruzetta**
}

\begin{abstract}
RESUMO
O presente artigo tem como objetivo refletir sobre a relação entre educação e democracia a partir da análise da desigualdade racial na representatividade de diretoras e diretores de/dos Centros Municipais de Educação Infantil (CMEIs) de Curitiba no ano de 2016. A abordagem metodológica consistiu em uma análise quantitativa na perspectiva de Selz (2015), entendendo que um conjunto de informações numéricas precisa ser nutrido de uma base teórica que possa explicar o fenômeno analisado. A discussão foi pautada na discussão da forma de provimento por indicação da função de diretora de CMEI e, para a compreensão da desigualdade racial na função, o argumento foi tecido a partir das teorias sobre desigualdades sociais que tratam sobre a estratificação, o uso de credenciais para distinção e as desigualdades no mercado de trabalho. Os resultados evidenciaram que a ocupação das direções de CMEIs tem maior proporção de autodeclarados brancos em relação à população paranaense. Como reflexão na relação entre educação e democracia, entendeu-se que a indicação como provimento da função de diretora pode potencializar a desigualdade racial já existente no magistério
\end{abstract}

*Faculdades São Braz. Colombo, Paraná, Brasil. E-mail: marcusquintanlha@hotmail.com - http://orcid.org/0000-0002-8305-0024

${ }^{* * *}$ Universidade Federal do Paraná. Curitiba, Paraná, Brasil. E-mail: nida_cruzetta@yahoo. com.br - http://orcid.org/0000-0002- 4708-7807 
pelas diferentes carreiras vigentes em Curitiba, além de impor obstáculos para a construção da democracia na comunidade escolar.

Palavras-chave: Gestão Democrática. Forma de provimento. Desigualdade racial. Curitiba. Educação Infantil.

\begin{abstract}
This article aims to reflect on the relationship between education and democracy based on the analysis of racial inequality in the representation of principals of the Municipal Centers for Early Childhood Education (CMEIs) of Curitiba in 2016. The methodological approach consisted of a quantitative analysis from Selz's perspective (2015), understanding that a set of numerical information needs to be nourished by a theoretical basis that can explain the analyzed phenomenon. The discussion was guided by the discussion of how the position of CMEI director is filled by appointment and, to understand racial inequality in the function, the argument was based on theories of social inequalities that deal with stratification, the use of credentials for distinction and inequalities in the labor market. The results showed that the occupation of the directors of CMEIs has a higher proportion of self-declared whites in relation to the population of Paraná. As a reflection on the relationship between education and democracy, it was understood that the nomination of the function of director may enhance the racial inequality that already exists in the teaching profession due to the different careers in force in Curitiba, besides imposing obstacles to the construction of democracy in the school community.
\end{abstract}

Keywords: Democratic management. Form of provision. Racial inequality. Curitiba. Child education

\title{
Introdução
}

A gestão democrática no ensino público brasileiro é prevista como um princípio educativo nas principais normativas educacionais do país (BRASIL, 1988, 1996, 2014). Todavia, o princípio da democracia na escola tem como premissa um conjunto de normas para a formação de decisões coletivas (BOBBIO, 2015) que, quase em sua completude, são definidas pelos sistemas de ensino, amparadas pela legislação vigente (BRASIL, 1996).

O problema decorre que, em determinados contextos, a democracia como princípio educativo pode encontrar obstáculos na normatização dos sistemas de 
ensino de determinadas ocupações de funções, como é o caso da direção escolar. No Brasil, a forma de provimento para esta função nas escolas municipais brasileiras é predominantemente por indicação (SILVA; CRUZETTA, 2018), ocupação dada predominantemente por aspectos políticos, que pode ser um entrave para a efetividade de uma gestão democrática e, consequentemente, de maior envolvimento da comunidade escolar nas tomadas de decisão e construção da importância da participação social nas decisões que envolvem a coisa pública.

A democracia como princípio de gestão e processo educativo, sejam no âmbito da formação dos estudantes ou da construção de coletividades na comunidade escolar, se faz sobretudo na ampliação da participação, do diálogo, da alteridade e do fortalecimento de instâncias colegiadas para que a maior quantidade possível de pessoas esteja envolvida na tomada de decisões que influenciem os rumos da escola (SOUZA, 2007, 2012). Além disso, o pleno exercício da democracia pressupõe uma superação das desigualdades sociais (e acrescenta-se as raciais) enraizadas no país, para que de fato haja a possibilidade de emancipação do indivíduo (SOUZA, 2007).

No que tange à análise das desigualdades, apesar de a renda se constituir como uma variável importante, a complexidade social contemporânea exige a investigação de outros fatores como formação, status, raça, entre outros são fundamentais para a análise das desigualdades (LIMA; PRATES, 2015; LIMA, 2012). Tendo essa afirmativa como ponto de partida, decorre que a representatividade racial também é uma questão importante que, implicitamente, pode ser um elemento importante na relação entre educação e democracia. Quando esta é incipiente, a democracia na sua essência não se efetiva.

Nesse sentido, o presente artigo tem como objetivo refletir sobre a relação entre educação e democracia a partir da análise da desigualdade racial na representatividade de diretoras e diretores dos Centros Municipais de Educação Infantil (CMEIs) de Curitiba no ano de 2016.

Como metodologia de pesquisa, primeiramente, construiu-se um arcabouço teórico de discussão acerca do cargo de diretor de CMEI como uma função de poder (SOUZA, 2007, 2012; WEBER, 2015), que gera a possibilidade de crescimento na carreira profissional dos professores, tornando-se uma credencial de distinção (COLLINS, 1974; DUBET, 2014). Sendo assim, o argumento construído transitou na ideia de como a forma de provimento por indicação pode aumentar a desigualdade racial já existente no magistério pelas diferentes carreiras vigentes na Rede Municipal de Ensino (RME) de Curitiba, além de se caracterizar como um obstáculo para a efetividade da democracia na escola.

A análise das informações pautou-se em dados primários, provenientes de uma coleta realizada no ano de 2016 com as diretoras de CMEI da Rede Municipal de Ensino (RME) de Curitiba, bem como nas informações do Censo 
Escolar do Instituto Nacional de Estudos e Pesquisas Educacionais Anísio Teixeira (Inep) e na Pesquisa Nacional por Amostra de Domicílios (PNAD) promovida pelo Instituto Brasileiro de Geografia e Estatística (IBGE), todos do ano de 2016, para discutir a desigualdade racial existente na função de diretor.

Nessa leitura, considera-se de importância a abordagem quantitativa na perspectiva de Selz (2015), pois, mesmo que o envolvimento de dados primários (coletados pelos autores a partir de instrumentos próprios) e secundários (pesquisadores investigam informações partir de coletas realizadas em outros âmbitos de pesquisa) para o entendimento da proposta de investigação seja a base empírica, compreende-se que a estatística neste trabalho é um meio auxiliar para a compreensão do fenômeno. Na perspectiva da autora, as informações numéricas em trabalhos de natureza sociológica ganham relevância se nutridas de arcabouço teórico que as auxilie a compreender o fenômeno.

Para fins de fomento da discussão sobre a indicação de profissionais ao cargo de diretora, como é o caso do provimento das dirigentes de CMEI em Curitiba-PR, a primeira seção deste trabalho se dedicou a uma discussão inicial acerca da função de diretor escolar, sua face política e de poder, bem como a indicação como uma forma de provimento que amplia a ligação política e o clientelismo entre o indicado e a secretaria de educação.

\section{A função de diretora como um espaço privilegiado de poder nos CMEIS de Curitiba}

Se a gestão é a execução da política e a diretora é a condutora desse processo, há uma face política da função, bem como da gestão escolar (SOUZA, 2012). Para compreender a função de dirigente como um lugar privilegiado nas relações da escola, parte-se do conceito de poder de Max Weber:

poder significa toda probabilidade de impor a própria vontade numa relação social, mesmo contra resistências, seja qual for o fundamento dessa probabilidade [...] dominação é a probabilidade de encontrar obediência a uma ordem de determinado conteúdo, entre determinadas pessoas indicáveis (WEBER, 2015, p. 33). 
Em seu esquema conceitual, Weber apresenta três tipos puros de dominação, colocando que sobre toda relação humana há uma relação de poder. O sociólogo discute ao longo de sua obra três tipos puros de dominação legítima, pois para cada tipo de dominação existe uma legitimidade que pode ser de caráter racional, de caráter tradicional e de caráter carismático.

A dominação racional legal é "baseada na crença na legitimidade das ordens estatuídas e do direito de mando daqueles que, em virtude dessas ordens, estão nomeados para exercer a dominação" (WEBER, 2015, p. 141). No caso da dominação tradicional, é caracterizada pela "crença cotidiana na santidade das tradições vigentes desde sempre e na legitimidade daqueles que, em virtude dessas tradições, representam a autoridade", enquanto a carismática se baseia "na veneração extra cotidiana da santidade, do poder heroico ou do caráter exemplar de uma pessoa e das ordens por esta reveladas ou criadas" (WEBER, 2015, p. 141), Entretanto, o autor reconhece que sua teoria de dominação não acontece na prática em seus tipos ideais puros de forma isolada, são frutos de metodologia de construção de matrizes, mas que costumam ser observadas em conjunto.

O destaque para a dominação racional legal neste trabalho é que ela implica numa burocracia de tipo ideal. Para o autor, administração burocrática significa dominação em virtude de conhecimento; este é seu caráter fundamental e especificamente racional. Além da posição de formidável poder devido ao conhecimento profissional, a burocracia (ou quem dela se serve) tem a tendência de fortalecê-la ainda mais pelo saber prático de serviço: o conhecimento de fatos adquirido na execução de tarefas ou obtido via "documentação". O conceito (não só mais especificamente) burocrático do "segredo oficial" - comparável, em sua relação ao conhecimento profissional, aos segredos das empresas comerciais no que concerne aos técnicos - provém dessa pretensão de poder (WEBER, 2015, p. 147).

Dessa maneira, a diretora é considerada uma burocrata que desenvolve sua função através da dominação do tipo racional legal. É por meio do seu conhecimento técnico da função e do poder que a lei lhe atribui que a dirigente escolar exerce a dominação sobre os outros funcionários do seu quadro administrativo, mesmo que se considere que há formas de dominação tradicional e carismática na função supracitada. Além disso, é a diretora que coordena as relações dentro desse ambiente, utilizando para isso a política e seu conhecimento técnico da função. Em suma, "o poder desempenhado pela condução da gestão escolar é uma forma de dominação" (SOUZA, 2012, p. 160).

Na visão de Weber (2015), política significa disputa de poder, que também se disputa nas relações. No caso da direção escolar, quem tem poder controla as relações por meio das tomadas de decisão (SOUZA, 2012). Porém, a diretora, particularmente de CMEI no município de Curitiba - PR, não é caracterizada 
como uma diletante, pois essas são especialistas que entendem tecnicamente a educação, ela não é leiga. Como afirma Souza (2007, p. 170), "o diretor não é um diletante, ao contrário, é um especialista, dominador do objeto e do campo do conhecimento em que atua a instituição escolar". A pessoa que opera no topo não tem um papel apenas técnico, mas também político, pois lida com os conflitos provenientes da disputa de poder. A diretora é uma burocrata no sentido que tem domínio técnico da função e uma especialista e opera politicamente a partir desse domínio.

O senso comum costuma confundir o papel da diretora escolar com a própria gestão escolar. A diretora é aquela que executa o processo da gestão escolar, é a que tem o conhecimento técnico da função e dirige o processo. A diretora tem a função de coordenar o trabalho geral da escola, coordenar as atividades que ali são realizadas. Para Souza, (2007, p. 153), “o diretor é o coordenador do processo político que é a gestão da escola, é entendido como o executivo central da gestão escolar". Em outras palavras, pode-se afirmar que, na escola, o domínio legítimo sobre as relações de poder é, de fato, o domínio sobre os processos de gestão escolar. A condução desta tarefa primeira dos dirigentes escolares não é por eles executada quando não detêm o domínio sobre as relações de poder (SOUZA, 2012).

A diretora também precisa administrar as demandas advindas da mantenedora e da comunidade escolar, pois, ela é ao mesmo tempo representante da comunidade e do Estado na instituição. Dessa maneira, é reforçada a ideia da face política da função da diretora, que está lidando cotidianamente com as relações de poder.

O modelo de assunção dessa profissional até a função de diretora, denominada nesse trabalho como forma de provimento, não tem regulação específica no âmbito nacional, mesmo que se reconheça que a legislação nacional vigente elenca a gestão democrática como um princípio de ensino nas escolas públicas brasileiras (BRASIL, 1998, 1996). A consulta à comunidade escolar para escolha dos diretores não é abordada nesse princípio, mas entendida como uma das estratégias para que a meta 19 do Plano Nacional de Educação em vigência seja efetivada (BRASIL, 2014), particularmente por ser a forma de provimento da diretora escolar que mais se aproxima do conceito de gestão democrática (SOUZA, 2007).

No caso do município de Curitiba - PR, ao ser nomeada para a função pela Secretaria Municipal de Educação (SME) através de uma portaria, a dirigente está legitimada para ocupar um lócus de poder no CMEI. Ela está nomeada para ser gestora de uma estrutura burocrática de dominação racional legal na instituição educativa. Essa dominação está baseada em estatutos, normas de uma Rede de Ensino e dessa forma “obedece-se à ordem impessoal, objetiva 
e legalmente estatuída e aos superiores por ela determinados, em virtude da legalidade formal de suas disposições e dentro do âmbito de vigência destas" (WEBER, 2015, p. 141).

A forma de provimento dos diretores dos CMEIs em Curitiba é realizada por indicação via portaria. Até o ano de 1987, havia concurso para o cargo de diretora de CMEI, denominado de administrador de creche, e em 2016 havia na rede ainda 10 diretores advindos desse processo atuando nas unidades. $\mathrm{O}$ provimento por indicação pressupõe um problema de legitimidade democrática, pois a diretora não foi escolhida pela comunidade escolar para ali estar e sim enviada por um político ou técnico da secretaria de educação, devendo a este primeiro a representatividade e não o compromisso com as famílias, professoras e demais segmentos da comunidade. Dessa forma, a indicação é caracterizada como um cargo de confiança do governo, que carrega fortes marcas do clientelismo político favorecendo formas de gestão mais patrimonialistas (SILVA; CRUZETTA, 2018). Sendo assim, a diretora responde primeiro às prioridades do governo, sendo desse uma representante.

Não se pode negar que a forma de provimento pela indicação é uma escolha que reconhece a face política da função, pois como afirma Souza (2007, p. 166), "do contrário não haveria disputa na definição de quem indicaria quem para ocupá-lo. Mas também significa uma forma patrimonialista de perceber a política e a própria educação". Dessa forma, se reforça a ideia da necessidade de se ter formas de escolha de diretoras que sejam mais democráticas.

Para esta indicação, não existem critérios estabelecidos para as diretoras de CMEIs no município analisado. A indicação é realizada pela SME e na maioria das vezes a pessoa indicada que está pleiteando a "vaga" para a função de diretora, passa por entrevistas pela chefe do Núcleo Regional de Educação, pela diretora do Departamento de Educação Infantil (EEI) e pela Secretária Municipal de Educação. Após a sua aprovação, ela é nomeada via portaria assinada pelo prefeito da cidade. O sujeito que é nomeado recebe um aporte em sua remuneração para exercer a função, denominada com Função Gratificada (FG). Assim, como o responsável pela nomeação, a destituição da função pode ocorrer por vontade do chefe do poder executivo, com ou sem motivos para tal. Sendo assim, a indicação não tem um tempo pré-determinado para findar. Dessa forma, tanto a nomeação como a destituição acontecem com base em critérios subjetivos, pessoais e políticos, pois eles não são normatizados.

A falta de critérios para a realização das indicações pode ser percebida pela variação das características técnicas que são consideradas nas pessoas que são nomeadas para ocupar a função de diretora, não havendo uma constância de exigência com relação à formação, à experiência com educação, à experiência na área da Educação Infantil, no tempo e no cargo que ocupa na RME de Curitiba, 
entre outros. Vale ressaltar que, a depender do perfil da gestão municipal que está no governo, essas características variam mais ou menos na escolha dos sujeitos. Essa organização reforça que a escolha por indicação se caracteriza muito mais como um ato político do que como um ato de escolha técnica, favorecendo assim o fortalecimento de um cargo de confiança, o que abre espaço para um clientelismo nas unidades educacionais, possíveis troca de favores e até apadrinhamentos, já que não são especificados os critérios utilizados para a escolha (MENDONÇA, 2000).

Reconhecendo a característica local da forma de provimento dos diretores de CMEI e a face política e burocrática de seu trabalho, a próxima seção visa discutir a questão da desigualdade racial no trabalho.

\section{Desigualdade racial no mercado de trabalho}

Não é raro de ver dois conceitos importantes serem tratados como sinônimos: diferença e desigualdade. É comum encontrar discursos que afirmam que somos diferentes por natureza para se justificar as desigualdades, diferença que de fato existe. Porém, quando essa diferença gera uma desvantagem para a pessoa, precisamos considerar como uma desigualdade, como é o caso da raça/ cor no mercado de trabalho, pois é a falta de um tratamento igualitário que gera a desigualdade e não a diferença em si (DUBET, 2014).

Pode-se considerar que a desigualdade racial é estrutural em nosso país. Essa desigualdade estrutural no mercado está marcada pela passagem do trabalho escravo para o trabalho livre (JACCOUD, 2008) e acaba gerando outras desigualdades consideradas dinâmicas, devido a organização da nossa sociedade (FITOUSSI; ROSANVALLON, 1996). Desta forma, torna-se necessário olhar para as desigualdades raciais no trabalho, nos diferentes estratos ocupacionais, nas funções de poder e liderança que potencializam uma organização social por status, fazendo uso de credenciais.

A discussão sobre grupos de status está inserida no debate trazido por Collins (1971), onde apresenta a Teoria do Conflito da Estratificação para problematizar os requisitos técnicos. Para o autor essa teoria está ancorada em três pilares: existem distinções entre as culturas dos grupos de status com base na classe social e na etnia; grupos de status tendem a ocupar funções de liderança e poder dentro das organizações; e ocupantes de diferentes posições institucionais lutam pelo poder. 
Grupos sociais organizados socialmente revelam a estratificação existente. Porém, essa estratificação não se faz apenas pela divisão de classe, não se pode considerar a homogeneidade das classes. Por essa razão, Collins (1971) argumenta que os grupos de status e a inflação das credenciais são uma forma de se manter a elite, manter os grupos de status fechados, discussão pautada na Teoria do Conflito da Estratificação.

Collins (1971) descreve como grupo de status membros que compartilham de uma cultura ou subcultura comum. Em geral são grupos compostos por pessoas que compartilham de um senso de igualdade de status, havendo assim uma distinção entre as pessoas que participam de diferentes grupos, para o autor

A participação em tais grupos culturais dá aos indivíduos seu senso fundamental de identidade, especialmente em contraste com os membros de outros grupos associativos em cuja cultura cotidiana eles não podem participar confortavelmente. Subjetivamente, os grupos de status se distinguem dos outros em termos de categorias de avaliação moral, como "honra", "gosto", "criação", "respeitabilidade", "propriedade", "cultivo" ("bons companheiros", "pessoas comuns"), etc. Assim, a exclusão de pessoas que não têm a cultura de grupos é legitimada normativamente (COLLINS, 1971, p. 1009, tradução nossa).

A participação em um grupo de status tende a fazer diferença na disputa pelo poder e consequentemente na ocupação de cargos mais elevados nas instituições. $\mathrm{O}$ autor mostra que a ascensão profissional por vezes está marcada pelo interesse da elite da organização, pois pessoas que ocupam funções do alto escalão tendem a escolher indivíduos com as características do seu grupo de status como uma forma de se manter o poder.

Esses conflitos são baseados em culturas de status étnicas ou religiosas; sua intensidade aumenta e diminui com processos aumentando ou diminuindo a distinção cultural desses grupos e com a sucessão de vantagens e desvantagens estabelecidas pelos resultados anteriores dessas lutas que determinam os recursos organizacionais disponíveis para lutas adicionais. Processos paralelos de conflito cultural podem ser baseados em classes distintas, como nós11 como culturas étnicas (COLLINS, 1971, p. 1010, tradução nossa). 
Collins (1971) revela que as origens sociais têm efeito direto na vida profissional dos sujeitos, mesmo para aqueles que conseguem uma extensão maior nos seus anos de estudo, concluindo níveis educacionais mais elevados, e traz dados que apontam a discriminação contra os negros. Na discussão, o autor traz como hipótese que as habilidades técnicas são consideradas secundárias dependendo do tipo da disputa pelo poder.

As poucas mudanças que observamos nesse cenário em nossa sociedade atual decorrem de lutas e disputas dos grupos de status, dos movimentos sociais, do que uma necessidade econômica, disputas que só costumam ser efetivas em sociedades consideradas democráticas.

Lima e Prates (2015), mostram que no Brasil na década de 2000 houve um crescimento da proporção de negros em todas as classes ocupacionais. Porém, os autores mostram que esse dado deve ser relativizado com o dado do crescimento populacional que se autodeclarou negro, "Descontando esse aspecto, pode-se dizer que foi entre os não manuais de rotina (alto e baixo) e os manuais sem qualificação que ocorreu um crescimento de fato da ocupação" (LIMA; PRATES, 2015, p. 180, grifos do autor). Mostrando como a desigualdade entre brancos e negros permanece entre os cargos de liderança e poder.

A inflação das credenciais está ligada a manutenção dos grupos de status e essa hierarquização social se revela no mercado de trabalho através da hierarquização das funções. Para Dubet (2014, p. 22) "o trabalho confere um estatuto, garante uma posição numa ordem social". O autor em questão traz uma discussão do que são desigualdades justas/aceitáveis no trabalho, o que é considerado justo pelos trabalhadores e o que é injusto. Pois, o autor mostra que nem todas as desigualdades geram injustiças, que a desigualdade só acontece quando um princípio não está sendo garantido,

o justo é o que o costume interiorizado por cada um define como sendo justo em termos de respeito às posições, direitos e deveres. Não é porque a igualdade não é assegurada que o sentimento de injustiça emerge, mas porque as desigualdades hierárquicas legítimas são violadas (DUBET, 2014, p. 24).

Trazendo essa discussão para o objeto analisado no presente artigo, pode-se considerar que planos de carreira geram desigualdades justas, pois professores com mais tempo de serviço, com maior formação tendem a ganhar mais. A questão que se coloca neste trabalho é que quando a diferença racial se traduz na menor frequência de indicação de negras e negros para funções de liderança, deve-se considerar como uma injustiça, uma desigualdade não aceitável. 
Ao abordar os desafios da relação entre diversidade, desigualdades e relações étnico-raciais na educação, Gomes (2012) aborda que a raça como uma construção política e social é uma categoria na qual também se organiza todo um sistema de poder, exploração e exclusão, na qual a autora chamará de racismo. Ou seja, a partir de distinções genéticas e biológicas, buscam discursos que legitimem a exclusão racial. Se há distinção e consequente exclusão em um processo de escolha de dirigentes escolares, por exemplo, trata-se de racismo. Lima (2012, p. 235) reforça que a utilização da variável raça precisa ser levada em consideração nas pesquisas, pois estudos mostram que "preconceito e discriminação raciais estão intimamente associados à competição por posições na estrutura social, refletindo sobre diferenças entre os grupos de cor na apropriação de posições na hierarquia social". A autora destaca ainda que a rigidez social existente no Brasil se torna uma rigidez racial na qual a desigualdade racial aparece entre os mais escolarizados e nas oportunidades de ocupar cargos com status mais elevados. Sendo assim, é necessário problematizar a estrutura de oportunidades oferecida pelo mercado de trabalho, pois a autora mostra em seu trabalho que na região metropolitana de São Paulo a diferença de renda entre brancos e negros é assustadora, onde os brancos tendem a ganhar o dobro do que os negros.

Outra questão que se deve levar em consideração na discussão sobre desigualdade racial no Brasil é referente aos dados sobre a população negra ${ }^{1}$, pois na maioria das pesquisas (como Censo, PNAD, dados da Prova Brasil) realizadas existe um número considerável de pessoas que preferem não autodeclarar sua raça/cor, além de muitas pessoas terem dificuldade de se enxergar como parda ou preta. Esses dados, ou a falta deles, dificultam a análise e a elaboração de políticas públicas focadas para a discriminação racial, pois o percentual da população é o índice que as políticas focais utilizam para propor suas metas e objetivos. Essa e outras constatações são objeto de análise na seção posterior. pretas e pardas. 


\section{Diretoras de CMEI no município de Curitiba: a representatividade negra na função e os aspectos atinentes à relação entre educação e democracia}

Assume-se para esta pesquisa uma abordagem quantitativa, pois optou-se por abordar uma quantidade significativa de casos com variáveis previamente definidas. Entretanto, a perspectiva deste trabalho dialoga com a ideia de pesquisa quantitativa em sociologia proposta por Selz (2015), pois, para a autora, a estatística é um elemento de importância nesse tipo de trabalho, mas não único.

Para Selz (2015), a compreensão dos dados precisa ser nutrida de conhecimento teórico para que a estatística e a literatura caminhem de forma a elucidar um determinado fenômeno. Nesse sentido, apesar de a pesquisa se assumir em abordagem quantitativa, considera-se fundamental o diálogo da empiria com a teoria.

As fontes de informação utilizadas foram os dados da Pesquisa Nacional por Amostra de Domicílios (PNAD), realizada pelo Instituto Brasileiro de Geografia e Estatística (IBGE) para caracterizar por cor/raça a população brasileira e paranaense. Para a caracterização dos docentes, utilizou-se as informações do Censo Escolar do Instituto Nacional de Estudos e Pesquisas Educacionais Anísio Teixeira - Inep. A partir destas informações, a metodologia de análise consistiu em comparar este cenário com os dados primários construídos conjuntamente para pesquisas investigativas no município de Curitiba - PR (ARBIGAUS; CRUZETTA, 2017). Todas as informações são baseadas no ano de 2016.

Em caracterização inicial, no Brasil, de acordo com os dados do PNAD em 2016, realizada IBGE, a representatividade de brancos, pretos e pardos eram de $44,2 \%, 8,2 \%$ e $46,7 \%$, respectivamente, culminando em um percentual de $54,9 \%$ de negros. No caso do Paraná, essa representação por raça se diferencia do cenário brasileiro, na medida em que brancos são maioria, com $67,6 \%$. Pardos $(27,8 \%)$, pretos $(3,3 \%)$ e outras $(1,3 \%)$ complementam esse cenário.

Ou seja, a representatividade racial no Paraná é diferente do restante do Brasil, muito em decorrência do perfil de colonização e ocupação do espaço. Portanto, o parâmetro inicial de comparação entre os professores e professoras da rede municipal de ensino de Curitiba - PR e os que ocupam o cargo de direção nos CMEIs precisa ser relativizado em relação à população brasileira.

Mesmo em um contexto em que a democracia é tida como princípio de ensino no principal conjunto de leis que regem a educação no país (BRASIL, $1988,1996,2014)$ e da legislação complementar que norteiam os sistemas de ensino, ou seja, pautada em alguns apontamentos por regras escritas, ela não 
se efetiva somente a partir destas. No entendimento de Bobbio (2015), tais regras delimitam quem são os sujeitos que serão chamados para fazer parte de um processo de tomadas de decisão e, nesse sentido, a burocracia no sentido weberiano é fundamental, pois é a partir do que está escrito nas normas que é possível entender o ponto de partida da democracia como procedimento em um determinado lugar.

Contudo, no contexto delineado por Souza (2007), é pouco efetivo a construção de um ambiente democrático se há uma profunda desigualdade social. Para o autor,

pensar a democracia exige pensar as possibilidades reais de sua realização. Do contrário, trata-se apenas de uma democracia estética, na qual as pessoas atuam na esfera pública fazendo escolhas como uma ação que se basta em si mesma. A democracia se faz muito menos nas definições formais, constitucionais, dos direitos dos indivíduos, e muito mais pela ampliação real das condições de superação das desigualdades sociais (SOUZA, 2007, p. 146).

Nessa perspectiva trazida pelo autor, dois elementos são importantes para a discussão desse trabalho: a) não há democracia efetiva se as condições de reprodução social e pensamento não se pautam em uma transformação social, ou seja, que o indivíduo e a sociedade consigam se emancipar, compreender as desigualdades e saber o caminho para combatê-las, incluindo a urgência de dizimar a diferença racial como um provável gerador de desigualdade; e b) é, na ampliação do diálogo, participação e alteridade que a democracia reside e se efetiva (SOUZA, 2007). Nesse sentido, pensar em uma educação para a democracia é trazer para o interior das instituições educativas um ambiente que construa a importância da participação da comunidade escolar nas tomadas de decisão, inclusive na escolha de seus dirigentes. Esse é o ponto de partida na análise dos dados, pois, o que se tem inicialmente é que há uma forma de provimento de tais dirigentes que costuma ser um obstáculo para a construção de um espaço democrático, na medida em que não há consulta à comunidade para a escolha da diretora da instituição educativa daquela localidade e, como consequência, não se constroem possibilidades de ampliação da participação no processo de escolha dos dirigentes de uma instituição pública e, tampouco, do estabelecimento de um diálogo que possa discutir as futuras ações de uma dirigente escolar. 
A primeira informação explorada se refere ao perfil das professoras e professores públicos municipais da rede municipal de ensino de Curitiba - PR por estratificação racial autodeclarada. Das 23.153 professoras e professores vinculados à mantenedora em 2016, a maioria é constituída de brancos (72,2\%), com apenas $8,2 \%$ de negros. O panorama também é caracterizado pelo significativo percentual de não declarados (19,2\%). De todo modo, entre os docentes, os brancos são maioria proporcional, quando comparados ao percentual populacional por raça no estado paranaense.

A rede municipal de ensino de Curitiba é caracterizada pela maior quantidade de docentes que atuam no ensino fundamental. De acordo com as informações do Censo Escolar do Instituto Nacional de Estudos e Pesquisas Educacionais Anísio Teixeira - Inep, no ano de 2016, 16.535 docentes $(71,85 \%)$ eram vinculados ao ensino fundamental, enquanto 4.407 (19,03\%) à educação infantil e 2.111 (9,12\%) com vínculo em outras etapas e/ou modalidades. Destes docentes, há poucas diferenças de representatividade racial quando discriminadas por este critério.

Para realizar o estudo da representatividade racial dos diretores e diretoras dos CMEIs da rede analisada, utilizou-se como base os dados primários obtidos por Arbigaus e Cruzetta (2017), em que, um dos procedimentos metodológicos consistiu em um questionário respondido por 175 dirigentes no ano de 2016.

No que tange à autodeclaração racial, optou-se por trabalhar com as informações de 174 diretoras e diretores dos CMEIs da capital paranaense, visto que uma das diretoras não respondeu à questão. A representatividade racial reflete o cenário já apresentado em relação aos professores, mas com maior superioridade proporcional de brancos, seja em comparação aos docentes ou aos paranaenses. De acordo com as respostas, os diretores e diretores brancos representam 78,16\%. Em contrapartida, negros são representados por $18,97 \%$ dos casos.

A representatividade branca, superior à população paranaense e de professores, pode indicar o que Collins (1971) caracterizou como a inflação das credenciais, que está ligada a manutenção dos grupos de status e essa hierarquização social se revela no mercado de trabalho através da hierarquização das funções. A questão que se coloca na reflexão destas informações é se há uma distinção de grupos sociais, e aqui acrescenta-se étnicos, na indicação de profissionais para um quadro de profissionais com poder legitimado pela secretaria de educação.

Estes profissionais em que a forma de provimento é por indicação, não são necessariamente vinculados à mesma carreira. Dos 174 profissionais, 4 são educadores sociais, 60 são professoras de educação infantil, 53 são pedagogas e 54 profissionais do magistério vinculadas ao ensino fundamental. Complementam-se esse grupo 3 dirigentes de uma carreira em extinção, a de Administrador de Creche. 
Ao desagregar esses profissionais por vinculação profissional, o cenário apresentado indica que a representatividade branca é bem superior nas carreiras de pedagoga e profissional do magistério vinculado ao ensino fundamental. Apesar de a representatividade de professoras de educação infantil brancas ser significativa (65\%), ela é menor em relação à população paranaense por raça e, proporcionalmente bem menor que as demais vinculações profissionais supracitadas.

$\mathrm{Na}$ constatação supracitada, uma questão contextual é importante. No caso da rede municipal de ensino de Curitiba, a carreira de professora de educação infantil é diferente das carreiras de pedagoga e professora de ensino fundamental. Para o ano de 2019, por exemplo, uma professora de educação infantil em uma jornada de 40 horas tem um vencimento inicial $60 \%$ menor que um docente do ensino fundamental ou pedagoga com duas jornadas de 20 horas, $\mathrm{R} \$ 2.455,51$ e $\mathrm{R} \$ 4.089,68$, respectivamente.

O cenário supracitado auxilia a problematizar, a partir da questão da representatividade racial, que até nas carreiras docentes para o município analisado, os indícios são de que a representatividade negra, que já é reduzida, é menor nas carreiras mais valorizadas e nas indicações para o cargo de diretor ou diretora de CMEI.

TABELA 1 - DIRETORES DE CMEI NO MUNICÍPIO DE CURITIBA-PR DISCRIMINADOS POR RAÇA E VINCULAÇÃO DE CARREIRA - 2016

\begin{tabular}{cccccc}
\hline Cargo & Amarelo & Branco & Não quero declarar & Pardo & Preto \\
\hline Educador (a) social & $25,00 \%$ & $75,00 \%$ & $0,00 \%$ & $0,00 \%$ & $0,00 \%$ \\
Outros & $0,00 \%$ & $33,33 \%$ & $0,00 \%$ & $66,67 \%$ & $0,00 \%$ \\
$\begin{array}{c}\text { Professor (a) de } \\
\text { educação infantil }\end{array}$ & $3,33 \%$ & $65,00 \%$ & $1,67 \%$ & $20,00 \%$ & $10,00 \%$ \\
$\begin{array}{c}\text { Profissional do magistério } \\
\text { (pedagogo (a)) }\end{array}$ & $0,00 \%$ & $92,45 \%$ & $1,89 \%$ & $5,66 \%$ & $0,00 \%$ \\
$\begin{array}{c}\text { Profissional do magistério } \\
\text { (professor (a)) }\end{array}$ & $0,00 \%$ & $81,48 \%$ & $0,00 \%$ & $14,81 \%$ & $3,70 \%$ \\
\hline
\end{tabular}

FONTE: Arbigaus e Cruzetta (2017).

Aqui se encontram duas abordagens teóricas. Dubet (2014) argumenta que existem desigualdades justas e injustas legitimadas no mercado de trabalho. Uma das desigualdades, presente na realidade escolar brasileira, é a distinção entre professores de diferentes etapas. Não somente no caso de Curitiba, mas no país, os professores públicos municipais de ensino fundamental tendem a receber maior remuneração pelo seu trabalho no comparativo com os profissionais do magistério da educação infantil (SILVA, 2019). 
A questão que se coloca é que, no caso do município analisado, a diferença de representatividade racial se reverbera nas carreiras onde se ganham mais. Particularmente, na função de diretora, os negros são proporcionalmente representados em escala menor no comparativo com a população local e o perfil racial dos professores públicos do município. Isso é justo? É uma desigualdade aceitável?

Uma segunda questão é relacionada às credenciais de distinção, conceito tecido por Collins (1971). Na análise de dados, percebe-se que a distinção começa na própria representatividade racial de professores concursados no município. Em relação à população paranaense, os brancos têm maior representatividade em relação aos negros, mas há distinções entre a proporção racial na educação infantil e ensino fundamental. Isso pode ser relacionado à exigência de formação inicial.

Considerando o ano de 2016 como base analítica, todos os professores do município eram contratados por via de concurso, ou seja, necessitando passar por um processo seletivo para que pudessem se vincular à rede. No caso dos professores do ensino fundamental, a exigência é de ensino superior (Pedagogia ou licenciatura plena somada curso de magistério). Na educação infantil, a exigência é somente do magistério, fato que é reconhecido pela literatura como um ponto de partida escolar que distingue carreiras e remuneração (SILVA, 2019).

A exigência de formação inicial pode indicar um retrato de distinção racial, estratificando proporcionalmente negros e brancos para carreiras e posições em que a diferença remuneratória amplie a desigualdade no mercado de trabalho. Estes aspectos auxiliam a compreender a importância de discutir a representatividade negra nos espaços de liderança, poder e maior remuneração a partir da ideia de credenciais de distinção (COLLINS, 1971), pois, a indicação é de que, possivelmente, mesmo com anos de dedicação de estudo iguais ou maiores que outros profissionais, os negros e negras podem estar sendo preteridos de espaços como a direção de CMEIs em Curitiba por não ter uma credencial que possibilite se inserir com representatividade significativa em espaços de poder como o supracitado.

As análises ora realizadas compõem um conjunto de fatores no município analisado que impõem obstáculos na construção de um espaço educativo democrático. A construção da democracia no espaço escolar tem como premissa a ampliação da participação de todas as pessoas envolvidas com o processo educativo, incluindo minorias historicamente relegadas desse processo, o que inclui a população preta/parda. No caso de Curitiba - PR, as contradições para a construção da democracia incluem a indicação política como forma de provimento do dirigente de CMEI e, especificamente como objeto de análise deste trabalho, a baixa representatividade racial dos supracitados. 
Nesse contexto, pensar em democracia onde não há, no mínimo, representatividade proporcional racial, é contraditório, pois não há regras escritas que garantam representatividade negra, diálogo e participação da comunidade para que elejam pretensas candidatas negras ao cargo e, em um avanço na discussão no contexto de uma comunidade escolar, a possibilidade de politizar coletivamente assuntos como a desigualdade social e racial. Esse é um ponto nevrálgico deste trabalho, pois não se pode afirmar que o racismo embasa provimento do cargo de dirigente escolar, mas que existe uma desproporção de representatividade negra nos cargos indicados para direções de CMEI no município analisado que traz a distinção racial como uma possibilidade explicativa do panorama.

Ademais, retoma-se a noção de desigualdade e diferença. A questão, que aqui não pode ser respondida, mas apresenta indícios para a discussão, é se o fato de ser negra ou negro é influente na (não) indicação de diretores e diretoras para os CMEIs do município analisado. Caso este seja um ponto, qualquer mudança estrutural só se efetiva a partir da luta e as disputas dos grupos de status, dos movimentos sociais, em prol da consideração da diferença, mas que isso não se mantenha como uma desvantagem.

\section{Considerações finais}

Este artigo teve como objetivo refletir sobre a relação entre educação e democracia a partir da análise da desigualdade racial na representatividade de diretoras e diretores de/dos CMEIs de Curitiba no ano de 2016. Nesse sentido, a discussão primeiramente perpassou pela natureza da função, em que o provimento é por indicação é uma forma de ascensão a um cargo iminentemente política e de dominação predominantemente racional legal. Posteriormente, o arcabouço teórico se dedicou a compreender a desigualdade racial no trabalho como um elemento presente na sociedade brasileira, bem como a diferença e desigualdade como questões a serem debatidas na análise de provimento de cargos de maior poder e remuneração. Essa discussão também foi pautada nos grupos sociais que geram diferentes credenciais de distinção, que podem ser influentes na ocupação destes espaços.

Os resultados indicaram que, no município analisado, a ocupação das direções de CMEIs é, proporcionalmente, maior em representatividade de autodeclarados brancos no contexto paranaense e, por consequência, curitibano. Nesse contexto, a reflexão proposta enfatiza que esse cenário impõe obstáculos 
para que o princípio da gestão democrática se efetive, seja pelo modelo de provimento da diretora e/ou pela baixa representatividade da população negra.

Ademais, considera-se que estudos dessa natureza sempre carecem de um aprofundamento qualitativo no sentido de observar como as decisões políticas de indicação acontecem e quais critérios são considerados (que não apresentam clareza) pelos sujeitos responsáveis pela indicação. Além disso, reitera-se a importância de considerar a representatividade racial como uma variável a ser investigada na desigualdade de provimentos de cargos, particularmente os que demandam maior remuneração e atribuição de poder.

\section{REFERÊNCIAS}

ARBIGAUS, Joelma de Souza; CRUZETTA, Danieli D'Aguiar. Perfil dos/as diretores/ as dos Centros Municipais de Educação Infantil de Curitiba - um estudo inicial. In: SIMPÓSIO BRASILEIRO DE POLÍTICAE ADMINISTRAÇÃO DAEDUCAÇÃO, 28., 2017. João Pessoa. Anais[...]. João Pessoa: Cadernos ANPAE, v. 45, 2017. p. 496-518. Tema Estados, Política e Gestão da Educação: tensões e agendas em (des)construção.

BRASIL. [Constituição (1988)]. Constituição da República Federativa do Brasil. Brasília, DF: Senado Federal, 1988.

BRASIL. Lei n ${ }^{\circ} 9.394$ de 20 de dezembro de 1996. Estabelece a Lei de Diretrizes e bases da Educação Nacional. Diário Oficial [da] República Federativa do Brasil, Brasília, 23 dez. 1996. Disponível em: http://www.planalto.gov.br/ccivil_03/leis/19394.htm. Acesso em: 11 mar. 2018.

BRASIL. Lei no 13.005 de 25 de junho de 2014. Aprova o Plano Nacional de Educação - PNE e dá outras providencias. 2014. Diário Oficial [da] República Federativa do Brasil, Brasília, DF, 11 mar. 2008. Disponível em: http://www.planalto.gov.br/ccivil_03/_ ato2011-2014/2014/lei/113005.htm. Acesso em: 20 jul. 2018.

COLLINS, Randall. Functional and Conflict Theories of Educational Stratification. American Sociological Review, [s.l.], v. 36, n. 6, p. 1002-1019, dez. 1971.

SILVA, Marcus Quintanlha da. CRUZETTA, Danieli D'Aguiar. O provimento do cargo do diretor como instrumento de gestão democrática e a qualidade da educação: análise das condições de oferta e resultados escolares. In: OLIVEIRA, Antonella de Carvalho (org.). Grandes temas da educação nacional. Ponta Grossa: Atena Editora, 2018. p. 78-92.

DUBET, François. Injustiças: a experiência das desigualdades no trabalho. Florianópolis: EDUFSC, 2014.

FITOSSI, Jean Paul; ROSANVALLON, Pierre. A nova era das Desigualdades. Paris: Éditions du Seuil, 1946. 
GOMES, Nilma Nilo. Movimento negro e educação: ressignificando e politizando a raça. Educ. Soc., Campinas, v. 33, n. 120, p. 727-744, jul./set. 2012

JACCOUD, Luciana. Racismo e República: O debate sobre o branqueamento e a discriminação racial no Brasil. In: THEODORO, Mário et al. (org.). As políticas públicas e a desigualdade racial no Brasil: 120 anos após a abolição no Brasil. Brasília: Ipea, 2008. p. 45-64.

LIMA, Marcia. "Raça" e pobreza em contextos metropolitanos. Tempo Social, revista de sociologia da USP, São Paulo, v. 24, n. 2, p. 233-254, nov. 2012.

LIMA, Marcia; PRATES, Ian. Desigualdades raciais no Brasil: um desafio persistente. In: ARRETCHE, Marta (org.). Trajetórias das desigualdades: como o Brasil mudou nos últimos cinquenta anos. São Paulo: Editora Unesp; CEM, 2015. p. 163-191.

MENDONÇA, Erasto Fortes. A regra e o jogo: democracia e patrimonialismo na educação brasileira. Tese (Doutorado em Educação) - Faculdade de Educação, Universidade Estadual de Campinas, Campinas, 2000. Disponível em: http://repositorio.unicamp.br/ jspui/handle/REPOSIP/251873. Acesso em: 12 jan. 2020.

SELZ, Marion. O raciocínio estatístico em sociologia. In: PAUGAM, Serge (org.). A pesquisa sociológica. Petrópolis, RJ: Vozes, 2015. p. 202-217.

SILVA, Marcus Quintanilha da. Remuneração de professores públicos municipais no Brasil: execução orçamentária, partidos políticos e valorização docente (2008-2016). 2019. Tese (Doutorado em Educação) - Programa de Pós-Graduação em Educação, Universidade Federal do Paraná, Curitiba, 2019.

SOUZA, Ângelo Ricardo de. Perfil da Gestão Escolar no Brasil. 2007. Tese (Doutorado em Educação) - Programa de Pós-Graduação em Educação, Pontifícia Universidade Católica de São Paulo, São Paulo. 2007.

SOUZA, Ângelo Ricardo de. A natureza política da gestão escolar e as disputas pelo poder na escola. Revista Brasileira de Educação, Rio de Janeiro, v. 17, n. 49, p. 159-174, jan./ abr. 2012.

WEBER, Max. Economia e sociedade: fundamentos da sociologia compreensiva. Tradução de Regis Barbosa e Karen Elsabe Barbosa. Revisão de Gabriel Cohn. 4. ed. Brasília: Editora Universidade de Brasília, 2015.

Texto recebido em 24/06/2020.

Texto aprovado em 08/12/2020. 